\title{
Design and Performance Research of Slotted- II Microstrip Patch Antenna for LTE Applications
}

\author{
M. Lakshmu Naidu, B. Rama Rao, C. Dharma Raj
}

\begin{abstract}
This paper propose the design of microstrip antenna which is used in cellular communication application especially at LTE network. The antenna was printed using FR-4 substrate material with dielectric constant of $\varepsilon r=4.4$ and thickness of $h=1.6 \mathrm{~mm}$. The overall dimension of the antenna is $135 \mathrm{~mm} \times 32 \mathrm{~mm} \times 1.6 \mathrm{~mm}$ with $50 \Omega$ impedance. This antenna operates between $400 \mathrm{MHz}$ to $900 \mathrm{MHz}$ for return loss of less than $-10 \mathrm{~dB}$. The simulation results suggest that the antenna gain is $4.725 \mathrm{~dB}$ with omni-directional radiation pattern. The antenna is designed to operate in the $2800 \mathrm{MHz}, 4100-6200 \mathrm{MHz}$, and $8.85 \mathrm{GHz} 10.00 \mathrm{GHz}$, frequency bands. The characterization of the antenna in free-space as well as in the proximity of the user hand is presented. The results confirm the excellent performance of the proposed diversity antenna.

Index Terms --- Long-Term Evolution (LTE), Wireless Fidelity (Wi-Fi), $\pi$-Shaped
\end{abstract}

\section{INTRODUCTION}

The evolution of wireless technology has grown dramatically. In the future, it is estimated that the need to access the internet will increase along with ever increasing human mobility. The presence of service for higher data rate will be the solution to answer the needs. In order to overcome this issue, LTE (Long Term Evolution) technology was launched.

LTE will be the step towards the fourth generation (4G) originated from radio technology which is designed to improve network capacity and speed LTE provides downlink capacity of at least100 Mbps and uplink capacity of at least $50 \mathrm{Mbps}$.

LTE is the project related to high performance air interface for mobile telephony. LTE is the latest new technology that ensures competitive edge over existing standards: GSM, UMTS, etc. It improves user understanding with full mobility. LTE minimizes the system and userequipment complexities.

Though microstrip antennas are much advantageous and it has low gain and narrow bandwidth are its limitations. In order to overcome these limitations, antennas with different feeding techniques have been observed.

Patch antenna can be fed mostly with coaxial probe feed [1], proximity coupled feed, aperture coupled feed and microstrip line feed [2]. Apart from these, antennas with elliptical slots [3], square slots [4-5], $\pi$ - shaped slots [6],

Revised Version Manuscript Received on August 14, 2019.

M. Lakshmu Naidu, Asst. Professor, Dept of ECE, Aditya Institute of Technology and Management Tekkali, A.P, India. (E- mail: laxman.naidu@gmail.com)

Dr.B. Rama Rao, Professor, Dept of ECE, Aditya Institute of Technology and Management Tekkali, A.P, India.

Dr.C. Dharma Raj, Professor, Dept of ECE, GIT , GITAM ( Deemed to be University), Vizag, A.P, India. double C-shaped [7], E-shaped [8] and with other geometries have been investigated [9].

In order to improve bandwidth of the antenna, one of the methods is adding parasitic elements [11], [12].

There are also many research and designs which discuss about wideband microstrip antennas working at certain frequency [12-14], however the authors have not found any research and design that discussed for $4 \mathrm{G}$ application that works at frequency from $800 \mathrm{MHz}$ up to $2400 \mathrm{MHz}$.

\section{DESIGN OF I SHAPED ANTENNA}

The design is simulated on Ansoft HFSS software. The designing of micro-strip antenna requires resonant frequency (f0), dielectric material and height of substrate (h). The proposed antenna is designed for frequency band $2.8-10 \mathrm{GHz}$.

The substrate used is FR-4 having dielectric constant $(\in r)$ 4.34 and height (h) $1.6 \mathrm{~mm}$. High dielectric constant is used for size reduction. The antenna is fed by $50 \Omega$ micro-strip line feed. It has a width $\mathrm{W}_{\mathrm{f}}$ and length $\mathrm{L}_{\mathrm{f}}$. The design formulas as given in [10] are as follows

1. Length of the patch $(\mathrm{L})=\frac{c}{2 f_{o} \varepsilon_{r}}$

where $\mathrm{c}=$ speed of the light in $\mathrm{m} / \mathrm{sec}=3 * 10^{8} \mathrm{~m} / \mathrm{sec}$

2. Width of the patch $(\mathrm{W})=\frac{c}{2 f_{o} \sqrt{\frac{\varepsilon_{r}+1}{2}}}$

3. Length of the micro-strip line feed $\left(\mathrm{L}_{\mathrm{f}}\right)=\lambda / 4$ where

Wavelength $(\lambda)=\mathrm{c} / \mathrm{f}_{0}$.

4. Width of the micro-strip line feed $=$

$\mathrm{W}_{\mathrm{f}}=7.48 \mathrm{~h} / e^{0.33(\mathrm{r}+1.41)}$

5. Position of inset feed $\left(\mathrm{y}_{0}\right)=\mathrm{R}_{\mathrm{in}}=\cos 2\left(\mathrm{y}_{0} / \mathrm{L}\right)$

The position of the inset feed is calculated from the above formula. Where $\operatorname{Rin}=$ input resistance $=50 \Omega$. In the wireless communication system, the role of antenna is very vital. Wireless technology application requires a tiny, light weighted, cheap and easy to install antenna, without compromising its performance Microstrip antenna meets several above requirements.

The special quality of microstrip antenna is its low profile and easy in realization. The proposed antenna dimension designed in this paper is $65 \mathrm{~mm} \times 42 \mathrm{~mm} \times 1.6 \mathrm{~mm}$ as shown in the Fig 1.

The designed antenna follows the antenna design with different shape of the patch. Besides, the antenna's ground plane is U Shaped for better return loss value. 


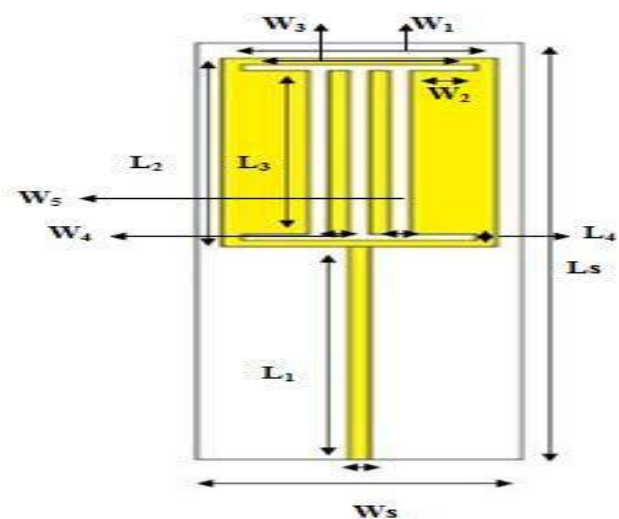

(a)

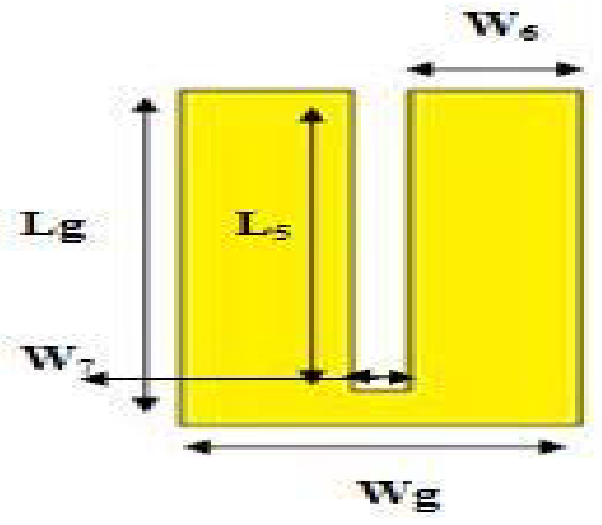

(b)

Fig. 1: Antenna Design (a) top view and (b) bottom view

\section{SIMULATION USING HFSS}

In order to test the proposed antenna structure, simulations are performed on Ansoft HFSS tool. In addition to reflection and transmission, quite a small number of nearfield parameters are also introduced for antenna performance evaluation. Fig. 2 shows the design of proposed antenna using HFSS simulation Solver.

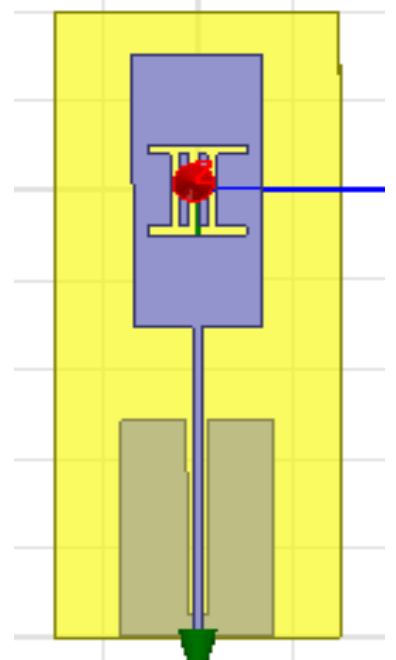

(a) Front View

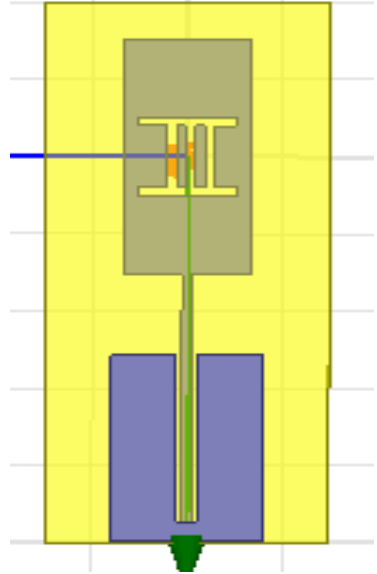

(b) Back View
Fig.2: HFSS design of Proposed antenna

\section{ANTENNA FABRICATION}

The simulated design is fabricated on FR-4 substrate of thickness $1.6 \mathrm{~mm}$ is shown in Fig.3.The desired shape is achieved by preparing the mask of the simulated design and then the prepared mask is printed on PCB for etching process and finally the SMA port is soldered for Testing. Fig. 4 shows Experimental setup for measuring the parameters on VNA

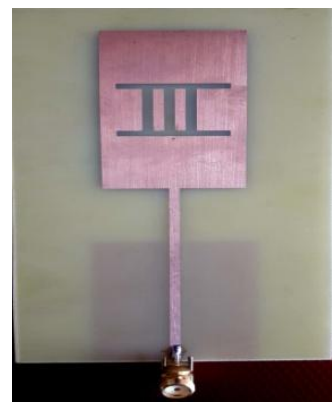

(a)Front View

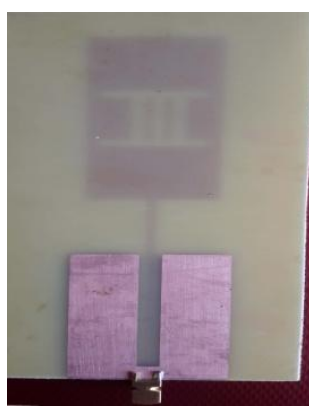

(b) Back View
Fig.3: Fabricated Antenna

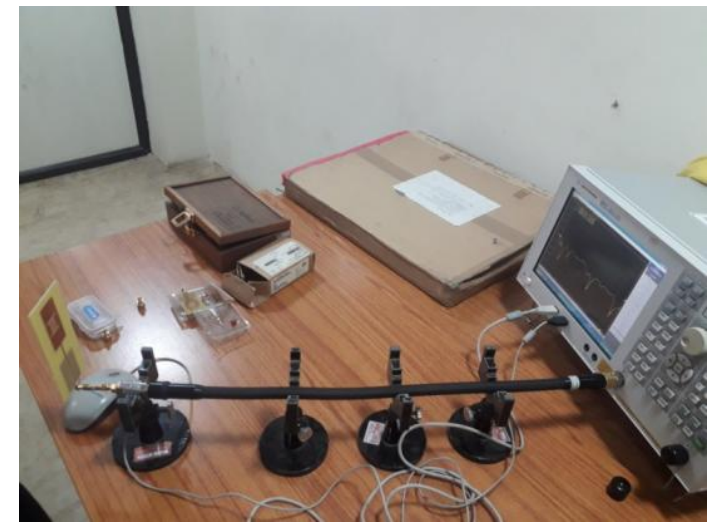

Fig. 4: Experimental setup for measuring the parameters

\section{RESULTS}

\section{i) Simulation Results}

The return loss for proposed monopole antenna is shown in Fig 5. From this figure observed that the return loss as $21 \mathrm{~dB}$ at $7.3 \mathrm{GHz}$ and range between $8.85 \mathrm{GHz}$ and $10.00 \mathrm{GHz}$ i.e., $1.2 \mathrm{GHz}$ band width lies below $-10 \mathrm{~dB}$.

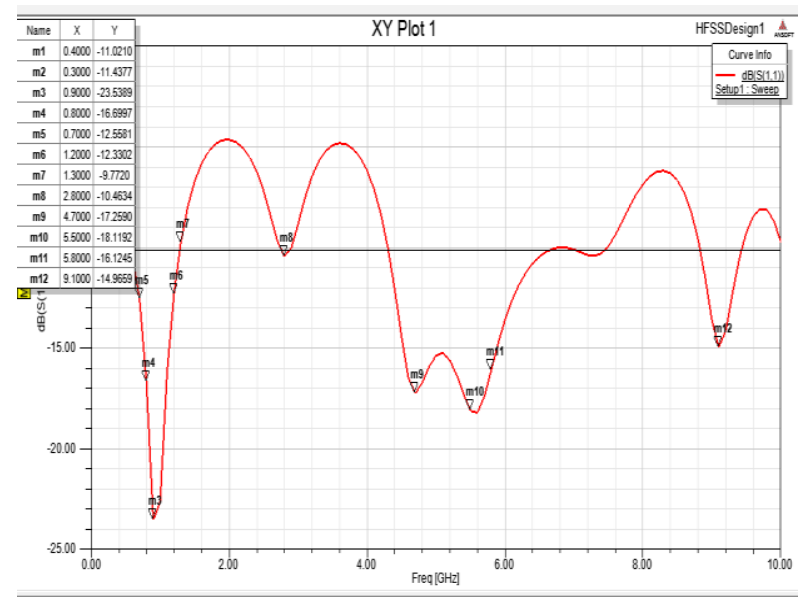

Fig. 5: Return loss of LTE Microstrip antenna 


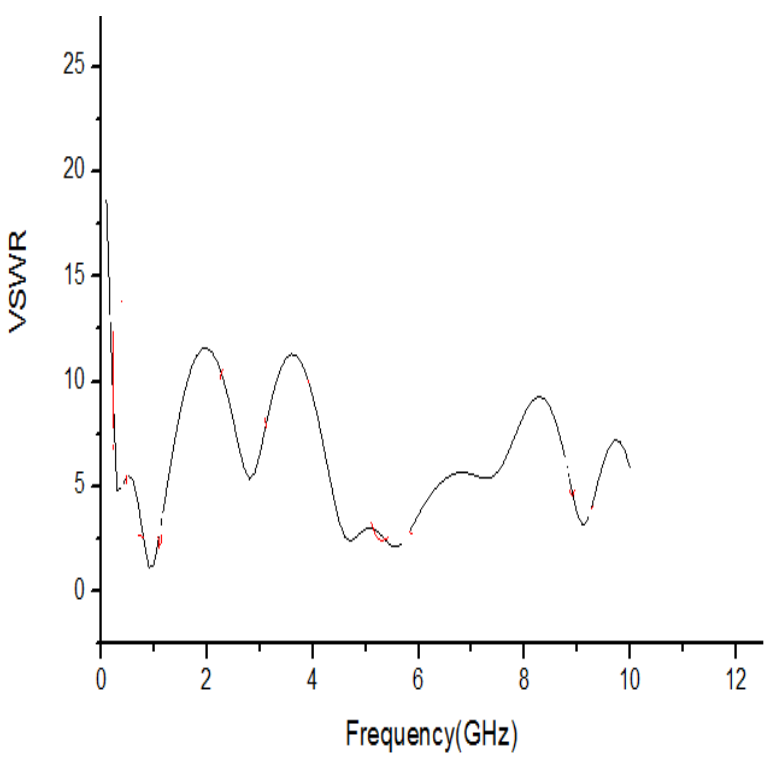

Fig. 6.VSWR of LTE Microstrip antenna

Fig.6 shows the VSWR of proposed antenna. When observed this Fig. the VSWR is less than 2 at $0.9 \mathrm{GHz}, 4.7 \mathrm{GHz}$ and $5.8 \mathrm{GHz}$.

\section{A. Parametric Study of the S-Parameters}

Parametric examination of the antenna is carried out to calculate approximately the effect of the parameters on the operating frequency. As described earlier, the antenna is designed to cover the LTE lower to operate in the 2800 $\mathrm{MHz}, 4100-6200 \mathrm{MHz}$, and $8.85 \mathrm{GHz}$ to $10.00 \mathrm{GHz}$, frequency bands. The antenna is optimized in an soft's HFSS to obtain minimum reflection and coupling between the antenna elements.

The reflection and coupling $S$-parameters of the optimal design are shown in Fig.5. A comparison is made with the HFSS simulations as well as with experimental results. It is observed that the undesired shifts in the resonant frequencies between the HFSS simulations and measurement results are due to the following factors: (1) manufacturing tolerances of the milling machine, (2) tolerances of manually adjusting the gap between the antennas and ground plane, and

(3) Uncertainty in the accurate dimensions of the SMA connector attached to the PCB grounding. From the HFSS results, the reflection coefficient is below $-10 \mathrm{~dB}$ over all desired bands. This is usually acceptable for handset antennas. Similarly, the Wi-Fi band is covered from 4.9 $\mathrm{GHz}$ to $5.9 \mathrm{GHz}$. The results obtained from HFSS and the experimental results on VNA also confirm the quad-band performance of the antenna. Nevertheless, the match in predicting the highest band is poor due to the fabrication tolerances.

\section{B. Gain}

Gain is a parameter that the power transmitted per unit solid angle. The 3-D gain of microstrip antenna designed in HFSS is shown in Fig 7 Gain of any antenna is more than $3 \mathrm{~dB}$ for any applications. The gain observed for this antenna is $4.725 \mathrm{~dB}$.

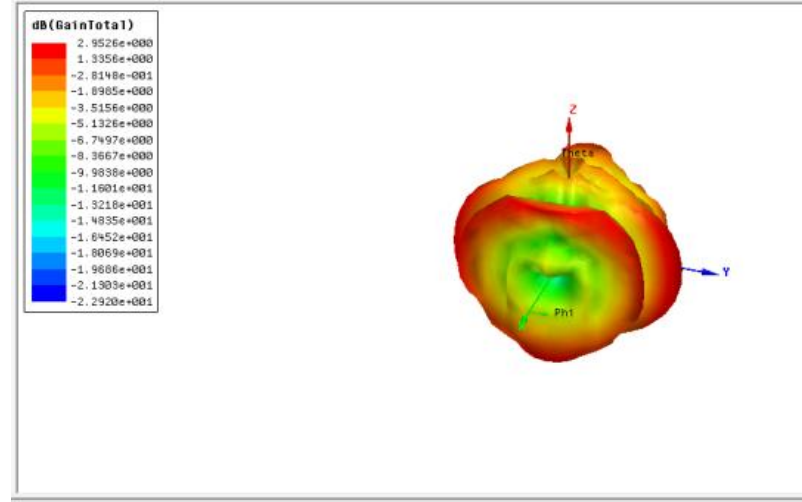

Fig. 7: Gain of microstrip antenna

\section{Far-Field Radiation Pattern}

The normalized three-dimensional (3D) radiation patterns of antenna in Fig.8 illustrate the simulated and measured 3D patterns for Antenna at the four operating frequency bands.
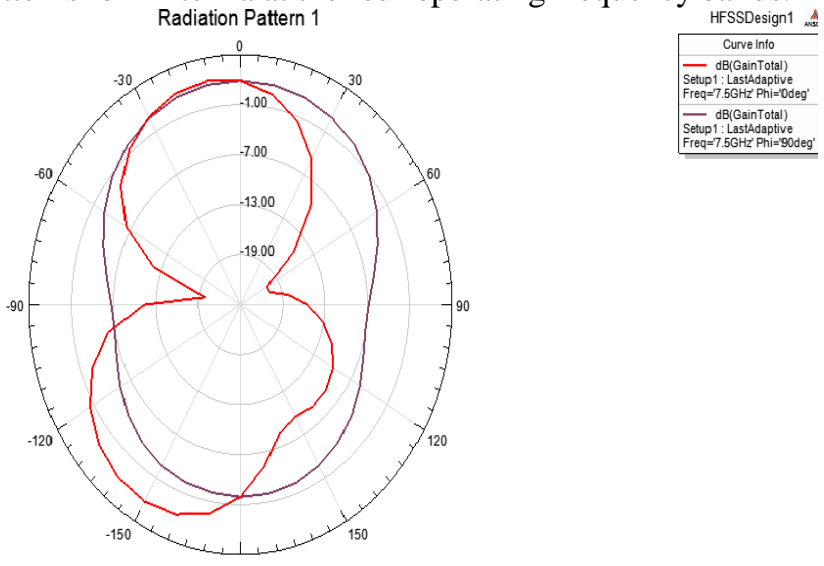

Fig.8: Radiation pattern of microstrip Antenna

Note that the antenna radiates nearly Omni-directional but the ground plane acts as a reflector directing power more toward the positive $z$-direction. Thus, the ground plane reduces the amount of transmitted power toward the human head.

Radiation Pattern of microstrip antenna is shown in Fig.8 represents gain vs theta and phi.

\section{Current Distribution}

To further investigate the high isolation between the antenna elements provided by the defected ground plane, HFSS was used to generate images of the surface current distributions when one antenna is excited while the other is terminated with a matched load. Fig 9 illustrates the current distributions at the four operating frequency bands. It is observed that most of the currents flow only nearby the excited antenna, allowing the two antennas to utility separately. The U-slot formed on the ground plane play a significant role in providing the high isolation preventing the current flow on the ground plane to reach the other antenna. 


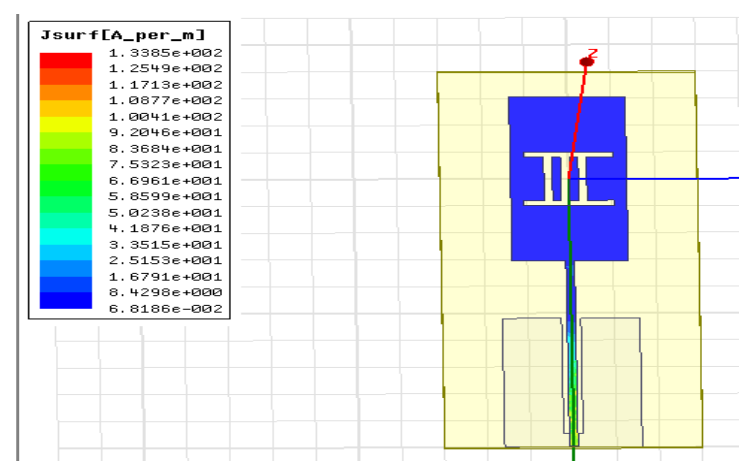

Fig. 9: current distribution of the microstrip antenna

ii) Measured Results

A prototype of the proposed antennas has been fabricated on FR-4 substrate and measured results on Vector network Analyzer for verification. The results show that the proposed antenna can achieve a very wide operating bandwidth with good radiation characteristics.

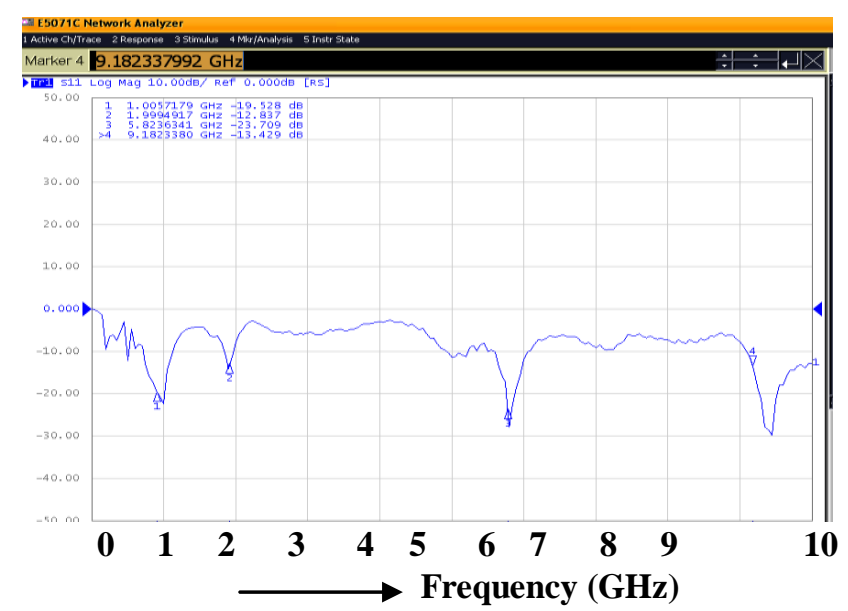

Fig.10: Return loss of fabricated antenna

The Fig.10 shows return loss curve for the proposed antenna measured by vector network analyzer.

It is observed that the antenna is resonating at two bands of frequency i.e. $1.99 \mathrm{GHz}, 5.82 \mathrm{GHz} \quad 9.18 \mathrm{GHZ}$ with return loss of $-12.837 \mathrm{~dB},-23.709 \mathrm{~dB},-13 / 429 \mathrm{~dB}$ respectively.

The antenna result a VSWR of lies between 1- 2 as shown in the Fig.11. VSWR is ideally one for perfectly matched.

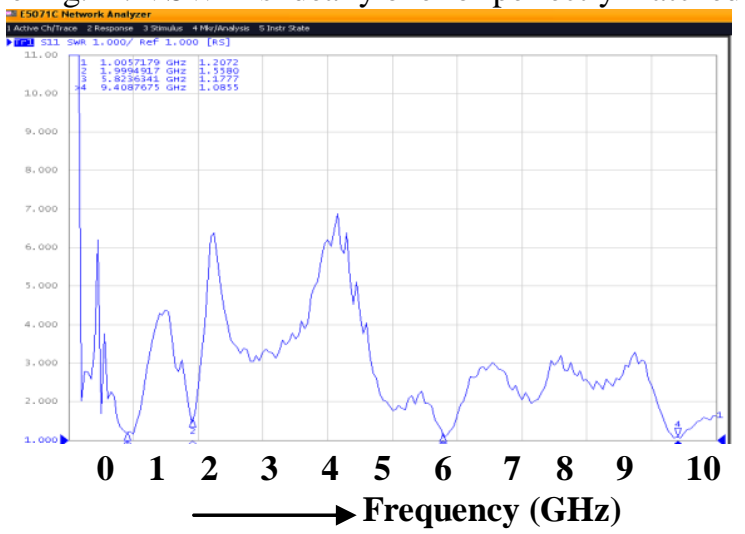

Fig .11: VSWR of fabricated antenna
Comparison of Theoretical and Practical Results

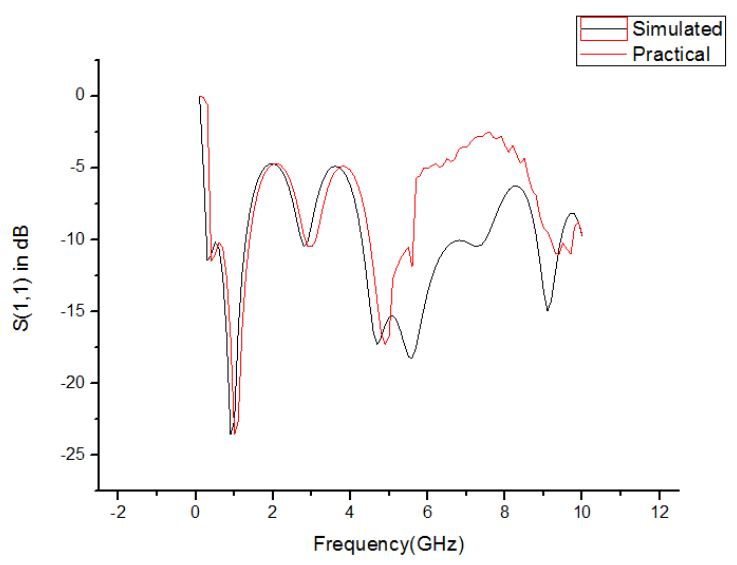

Fig .12: Comparison of return loss

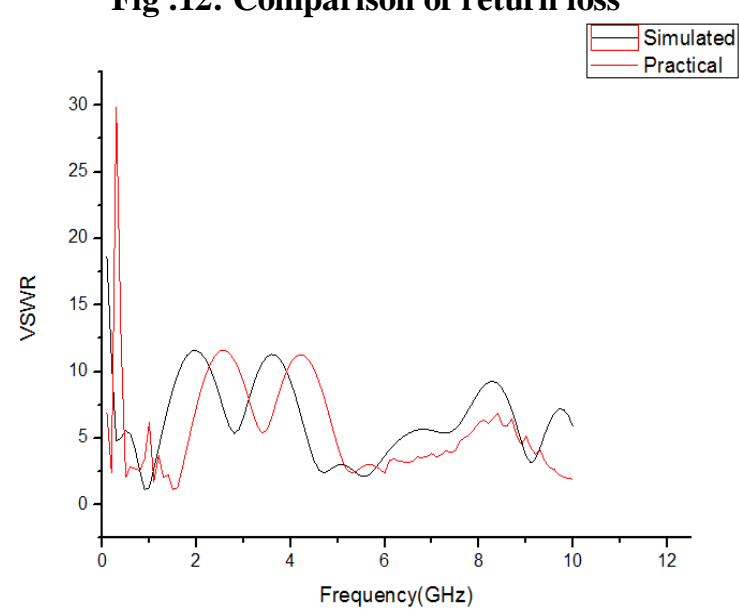

Fig .13: comparison of VSWR

\section{CONCLUSION}

In this paper, a unique design of the microstrip antenna such that it consists of $\pi$-shaped slot between the two slots on patch is proposed. Moreover a $\pi$-shaped slot bounded by another square with a rotation of at its symmetry and also it can be noted that the two square is again bounded by square shaped slot with larger area. The proposed antenna design is applicable for PCS and UMTS application with reported VSWR value is less than 2 The LTE band antenna supports various frequency bands such as $400 \mathrm{MHz}$ to $900 \mathrm{MHz}$, $2800 \mathrm{MHz}, 4100-6200 \mathrm{MHz}$, and $8.85 \mathrm{GHz} 10.00 \mathrm{GHz}$ for few GSM applications, Wi-Fi and Wimax applications. The small sized antenna serves for high range of frequencies used for LTE and microwave applications

\section{REFERENCES}

1. K. F. Lee, K. M. Luk, K. F. Tong, S. M. Shum, T. Huynh, and R. Q. Lee,"Experimental and Simulation Studies of Coaxially Fed U-Slot Rectangular Patch Antenna", Inst. Elect. Eng. Proc. Microwave Antennas Propagat., vol. 144, pp.354-358,1997.

2. S. Kapoor, D. Parkash, "Efficient Microstrip Fed Rectangular Patch Antenna with DGS for WLAN \& WiMAX Applications", IJERA Vol. 2, Issue 6, pp. 044-047, Nov.- Dec. 2012. 
3. P Kumar, A Kumar and Sonali Panda, "Design of a Unique Microstrip Antenna with Optimum Gain", International Conference on Communication and Signal Processing (ICCSP'15), Melmaruvathur, April 2015.

4. L. Agarwal, S. Gandhi, S. Malik, S. Vijay, T. S. Chauhan, "Design and Analysis of Rectangular Patch with Square Slots", International Journal of Scientific Research and Management Studies (IJSRMS), Vol. 3, Issue 1, pp. 15-20, ISSN: 2349-3771

5. R. Caso, A. Michel, A. Buffi, P. Nepa and G. Isola, "A Modular Antenna for UHF RFID NearField Desktop Reader", 2014 IEEE RFID Technology and Applications Conference (RFIDTA), pp. 204-207, 8-9 Sept. 2014.

6. Rahman, M. M., Hossain, M. M., and Karmakar, K. K., " $\pi$-shape Microstrip Antenna Design for Wi-MAX, Wi-Fi and Biomedical Application at 2.45 GHz", IEEE 3rd International Advance Computing Conference (1ACC), Ghaziabad, Uttar Pradesh, India, 22-23 Feb 2013, pp. 546-549.

7. P. Kumar, A. Kumar and S. Panda, "Design of double C-shaped microstrip antenna for application in UWB region", International Conference on Communication and Signal Processing (ICCSP'15), Melmaruvathur, April 2015.

8. Kumar, P. Kumar, A. Deb, “An E-shaped microstrip antenna with unidirectional propagation", International Conference on Communication and Signal Processing(ICCSP ${ }^{\text {ee }}$ 15), Melmaruvathur, April 2015.

9. M. Thomas, J. S. Roy, B. Gupta and A. Rydberg, "T - Coupled Microstrip Patch Antenna for WLAN", International Conference on ommunication and Electronics System Design, $876006 \quad$ (28 January 2013); doi: $10.1117 / 12.2009581$

10. Balanis, C. A . 2009. Antenna Theory: Analysis and Design. Wiley Publications.

11. T. Hidayat, F. Y. Zulkifli, E. T. Rahardjo (2013). "Bandwidth and GainEnhancement of Proximity Coupled Microstrip Antenna Using Side Parasitic Patch”. 2013 Int. Conf on Radar, Antenna, Microwave, Electronics and Telecommunications (ICRAMET)

12. Broadband Microstrip Patch Antenna with Parasitic Elemen". IJAREEIE Vol. 3 Issue 6, June 2014.

13. Kurniawan. S. Muklisin (2013). "Wideband Antenna Design and Fabrication for Modern Wireless Comunication System". The $4^{\text {th }}$ International Conference on Electrical Engineering and Informatics(ICEEI), 2013.

14. N. Khalid, S. Z. Ibrahim, M. N. A. Karim (2016). "Directional and Wideband Antenna for Ground Penetrating Radar (GPR) Applications"2016 3rd International Conference on Electronic Design (ICED), August 2016. 